\title{
Troca de facetas em resina composta insatisfatórias, buscando adequação anatômica e estética: relato de caso
}

Exchange of unsatisfactory composite resin veneers, seeking anatomical and esthetic adequacy: case report

Intercambio de carillas de resina compuesta insatisfactorias, buscando adecuación anatómica y estética: reporte de caso

Recebido: 13/10/2021 | Revisado: 20/10/2021 | Aceito: 26/10/2021 | Publicado: 30/10/2021

\author{
Alessandro Ítalo Cruz \\ ORCID: https://orcid.org/0000-0003-4679-7302 \\ Centro Universitário Tiradentes, Brasil \\ E-mail: Aleitalocruz@gmail.com \\ Giovana Lacerda Brandão \\ ORCID: https://orcid.org/0000-0001-9542-9659 \\ Centro Universitário Tiradentes, Brasil \\ E-mail: Giovana_lb@hotmail.com \\ Gyovanna Evelyn Alves Silva \\ ORCID: https://orcid.org/0000-0003-0782-5323 \\ Centro Universitário Tiradentes, Brasil \\ E-mail: gyovannaevelyn@outlook.com \\ Joedy Maria Costa Santa Rosa \\ ORCID: https://orcid.org/0000-0001-8486-0128 \\ Centro Universitário Tiradentes, Brasil \\ E-mail: joedysantarosa@ hotmail.com \\ Pedro Igor dos Anjos Melo \\ ORCID: https://orcid.org/0000-0003-1239-6199 \\ Centro Universitário Tiradentes, Brasil \\ E-mail: drpedroanjos@gmail.com
}

\begin{abstract}
Resumo
Atualmente as pessoas vêm cada vez mais tentando se enquadrar em um padrão de beleza e a busca pelo sorriso perfeito pode trazer danos e frustrações ao paciente, caso o profissional não siga os critérios necessários para realizar intervenções estéticas, como é o caso das facetas em resina composta. O objetivo deste trabalho é descrever um caso clínico onde foi realizada a troca de facetas em resina composta nos elementos dentários anteriores superiores por novas facetas de resina em busca de adequação estética e anatômica e discutir acerca desse tratamento. O paciente procurou atendimento no consultório odontológico queixando-se de suas antigas facetas, onde o mesmo achava a coloração desagradável, afirmando também que ao fazer sua higiene oral havia sangramento. Tendo em vista tais situações do paciente e análise clínica, foi proposto clareamento dental imediato da arcada inferior, remoção das 10 facetas pré-existentes e nova execução de 10 facetas em resina seguindo os princípios estéticos e funcionais. Para a realização de múltiplas restaurações estéticas é essencial que o Cirurgião-Dentista esteja atento às indicações, possíveis limitações e conhecimento da anatomia dental do paciente, respeitando também tecidos e estruturas periodontais. Sendo assim, um planejamento devidamente qualificado para executar tal procedimento é essencial para que o paciente não venha a ter qualquer tipo de desconforto, garantindo o sucesso do tratamento.
\end{abstract}

Palavras-chave: Resina Composta; Facetas dentárias; Estética dental.

\begin{abstract}
Nowadays, people are increasingly trying to fit a standard of beauty and the search for the perfect smile can bring harm and frustration to the patient, if the professional does not follow the necessary criteria to perform aesthetic interventions, as in the case of resin veneers composed. The objective of this work is to describe a clinical case where the replacement of composite resin veneers in the upper anterior dental elements by new resin veneers was performed in search of esthetic and anatomical adequacy and to discuss about this treatment. The patient sought care at the dental office complaining about his old facets, where he found the color unpleasant, also stating that when he performed his oral hygiene there was bleeding. In view of such patient situations and clinical analysis, immediate tooth whitening of the lower arch was proposed, as well as removal of the 10 pre-existing veneers and a new execution of 10 veneers in
\end{abstract}


resin following the aesthetic and functional principles. In order to perform multiple esthetic restorations, it is essential that the Dental Surgeon is aware of the indications, possible limitations and knowledge of the patient's dental anatomy, also respecting periodontal tissues and structures. Thus, a properly qualified planning to perform this procedure is essential so that the patient will not have any discomfort, ensuring the success of the treatment.

Keywords: Composite resin; Dental veneers; Dental esthetics.

\section{Resumen}

Hoy en día, las personas intentan cada vez más ajustarse a un estándar de belleza y la búsqueda de la sonrisa perfecta puede traer daño y frustración al paciente, si el profesional no sigue los criterios necesarios para realizar intervenciones estéticas, como en el caso de las carillas de resina compuestas. . El objetivo de este trabajo es describir un caso clínico donde se realizó la sustitución de carillas de resina compuesta en los elementos dentales anteriores superiores por nuevas carillas de resina en busca de adecuación estética y anatómica y discutir sobre este tratamiento. El paciente buscó atención en el consultorio odontológico quejándose de sus viejas facetas, donde encontró desagradable el color, manifestando además que cuando realizaba su higiene bucal había sangrado. Ante tales situaciones de pacientes y análisis clínico, se propuso el blanqueamiento inmediato de la arcada inferior, así como la retirada de las 10 carillas preexistentes y una nueva ejecución de 10 carillas en resina siguiendo los principios estéticos y funcionales. Para realizar múltiples restauraciones estéticas, es fundamental que el odontólogo conozca las indicaciones, posibles limitaciones y conocimiento de la anatomía dental del paciente, respetando también los tejidos y estructuras periodontales. Por ello, una planificación debidamente cualificada para realizar este procedimiento es fundamental para que el paciente no tenga ninguna molestia, asegurando el éxito del tratamiento.

Palabras clave: Resina compuesta; Carillas dentales; Estética dental.

\section{Introdução}

Nos últimos anos, as pessoas vêm buscando se enquadrar em um alto padrão estético do sorriso, esse que pode interferir diretamente na autoestima de muitos. Além disso, existe o desejo da aceitação social e em alguns casos, a necessidade de reabilitar alguma função perdida (Borges, et al., 2019).

As facetas em resina composta são uma das opções possíveis para solucionar a insatisfação estética, como alterações de tamanho, cor, forma, desalinhamento, espaços interdentários e também sequelas provenientes de cárie e outros possíveis problemas em dentes anteriores. Estão sendo cada vez mais utilizadas, pois os materiais adesivos e restauradores vêm adquirindo com o tempo mais qualidade estética e funcional do que os oferecidos anteriormente (Muziol, 2017 \& Patias, 2015).

Em resultado da grande busca pela harmonia do sorriso, os materiais odontológicos vêm apresentando avanços nas propriedades ópticas e físicas, favorecendo as técnicas conservadoras e por consequência auxiliando no alcance de resultados satisfatórios. Além disso, possibilitam um leque de procedimentos que podem ser realizados, permitindo indicar e planejar um tratamento personalizado para cada paciente, visando utilizar técnicas menos invasivas (Pereira, et al., 2020 \& Borges, et al., 2019).

A resina composta é um excelente material para a execução de facetas diretas. A técnica se destaca por consequência do material ter um excelente potencial para trazer de volta a função e longevidade. Além de preservarem a estrutura dental sadia, possuem o aspecto de naturalidade através da técnica de estratificação de cor, oferecem possibilidade de reparo e são uma alternativa de bom custo-benefício (Pereira, et al., 2020 \& Berwanger, et al., 2017).

Outra vantagem das facetas de resina, é que podem ser realizadas em sessão única, pois não requerem moldagens e confecção de provisório, dispensando as etapas laboratoriais, consequentemente proporcionando ao paciente um menor custo de tratamento (Borges, et al., 2019).

É muito importante que o profissional seja devidamente qualificado para executar esse tipo de procedimento, pois tratamentos feitos sem indicação, ou com um planejamento inadequado, podem trazer inúmeros malefícios à qualidade de vida do paciente. Logo de início deve ser feito um adequado exame clínico, a fim de avaliar a condição intra e extraoral do paciente, 
observando todos os elementos dentários, os tecidos moles, a oclusão e avaliando a condição do periodonto. (Borges, et al., 2019 \& Berwanger, et al., 2017).

As etapas de acabamento e polimento são essenciais para um sucesso estético e clínico, pois trazem como objetivo aumentar a lisura superficial, proporcionando uma aparência mais natural. Diante disso, o acabamento e polimento em resinas compostas são passos significativos para aprimorar a estética, aumentando a resistência da restauração, uma vez que, a execução de um correto acabamento e polimento reduz a probabilidade de adesão de placa bacteriana, minimiza a irritação da gengiva e problemas periodontais futuros, diminui o risco de infiltrações e cáries secundárias, aumenta a reflexão especular oferece a sensação de brilho mais natural, amplia a durabilidade e a resistência ao longo do tempo e essencialmente, traz satisfação e conforto ao paciente (Carvalho, et al., 2021).

As facetas proporcionam ao paciente um excelente resultado estético, entretanto, a utilização da mesma requer atenção para que não ocorram falhas. A incessante busca pelo sorriso perfeito, sem os critérios adequados, acaba gerando muitos problemas (Fontenele, 2019).

Além do domínio da técnica, o profissional deve conhecer a anatomia dental, ter respeito pela saúde gengival do paciente, levar em consideração doenças periodontais severas e dentes vestibularizados. É necessário que haja franqueza da parte do profissional, para que não alimente a expectativa sem sucesso do paciente, deixando falar mais alto o pensamento capitalista e ignorando a ética. Problemas como esses irão impedir um bom resultado, trazendo frustração ao paciente, e em muitos casos sendo necessário uma reexecução do trabalho (Fontenele, 2019).

O presente trabalho tem como objetivo apresentar falhas que podem ocorrer na execução de facetas de resinas diretas, sendo esses motivos de insatisfação do paciente, se fazendo necessário um novo planejamento e elaboração do trabalho para correção do caso, respeitando a anatomia, saúde periodontal e limitações do paciente, através de um profissional que possua o domínio da técnica.

\section{Metodologia}

A metodologia empregada neste artigo foi o relato de caso clínico com finalidade descritiva e de abordagem qualitativa. Na pesquisa descritiva realiza-se o estudo, a análise, o registro e a interpretação dos fatos do mundo físico sem a interferência do pesquisador (Barros \& Lehfeld, 2007). O estudo de caso considera um fenômeno individual com profundidade para compreender a situação. Tem como característica ser de cunho interpretativo, ao utilizar a descrição, ou avaliativo, empregando a descrição e a interpretação (Marconi \& Lakatos, 2008).

Segundo Pereira et al. (2008) a interpretação do pesquisador é fundamental para articular o conhecimento científico com os casos clínicos. Ressalta-se que a paciente autorizou a utilização do caso clínico para fins de pesquisa por meio do Termo de Consentimento Livre e Esclarecido (TCLE).

\section{Relato de caso}

Paciente C.R.L, gênero masculino, 38 anos, compareceu ao instituto Anjos Melo, queixando-se da harmonia do seu sorriso devido ao formato e coloração de suas facetas de resina composta e ainda relatou sangramento durante higienização das mesmas (Figura 1). Além disso, paciente apresentava problema de mobilidade após um acidente, tendo uma certa dificuldade para higienizar a cavidade oral. 
Figura 1: Desarmonia estética e invasão do espaço biológico.

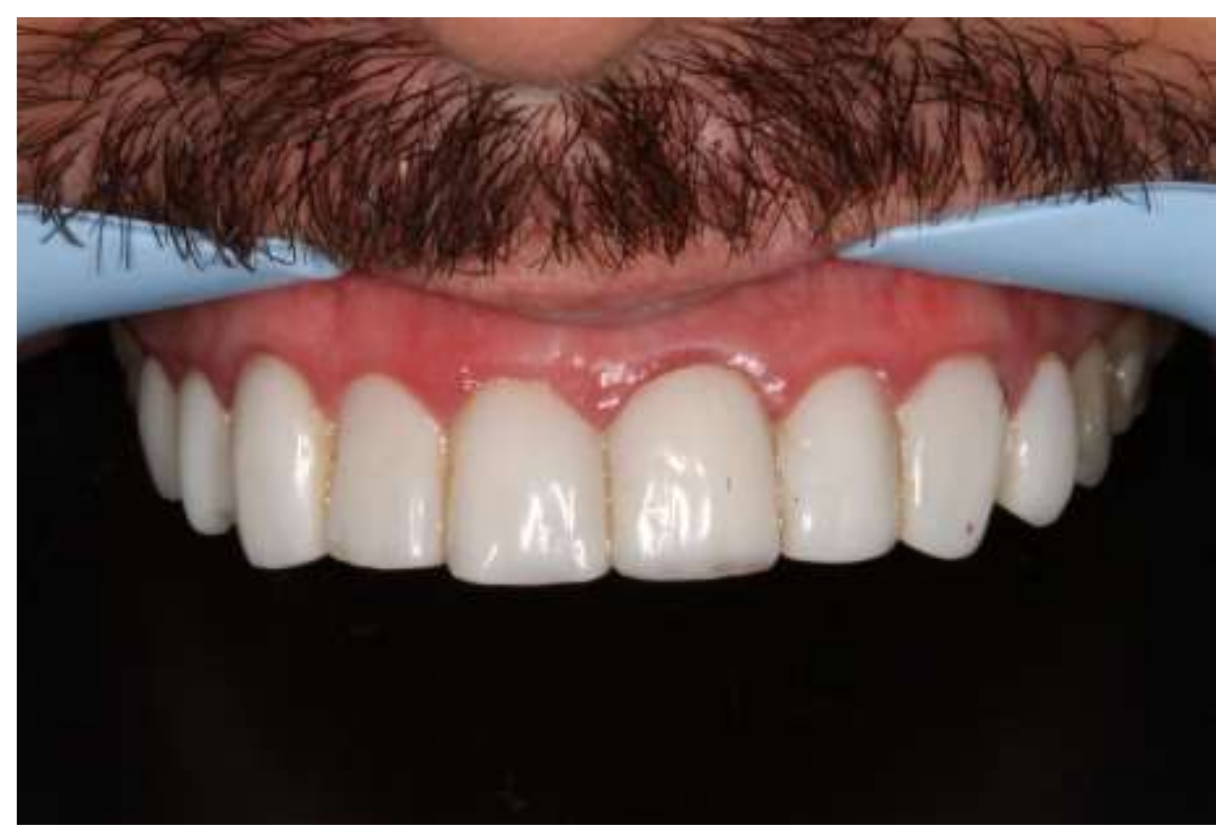

Fonte: Autores.

Aos exames clínico e fotográfico, foram encontrados erros na execução das facetas: anatomia inadequada, ausência de ponto de contato, acabamento e polimento mal executados, diferença de cor exorbitante em relação aos dentes naturais, trazendo um contraste insatisfatório e invasão do espaço biológico, causando inflamação na gengiva e consequentemente o sangramento durante a higienização dos dentes.

Após anamnese, exame clínico, análise de radiografia panorâmica e tomadas fotográficas iniciais, iniciou-se a elaboração do planejamento e plano de tratamento. Foi proposto ao paciente três sessões de clareamento em consultório na arcada inferior, a remoção das 10 facetas de resina pré existentes, profilaxia, reexecução das 10 facetas também em resina composta e por fim instrução de higiene oral.

O tratamento iniciou com profilaxia dos elementos dentários 35 ao $45 \mathrm{com}$ jato de bicarbonato utilizando a ultrassom, seleção da cor de acordo com a escala vita classica (VITA) onde foram registradas as cores A3 e D3. Em seguida foi realizado o isolamento relativo com abridor de boca e aplicação da barreira gengival TOP DAM (FGM). Após fotopolimerização da barreira, foi aplicado o gel clareador Whitness Perfect 35\% (FGM) sobre a superfície dos 10 dentes, onde este foi mantido por 45 minutos.

Após a terceira sessão do clareamento houve o alcance da cor DA1 e EA1 de acordo com a escala vita classical (VITA), demonstrando uma melhora significativa na coloração. Finalizando o tratamento clareador, foi dado um intervalo de oito dias para iniciação do tratamento restaurador.

Foi iniciado o tratamento com a remoção das antigas facetas, com isolamento absoluto modificado, utilizando a broca multilaminada 18 lâminas tronco cônica. Durante a remoção foram notados muitos excessos de resina, invadindo o espaço biológico e escurecimento do dente 21 (Figura 2). 
Figura 2: Dentes naturais após remoção das facetas antigas.

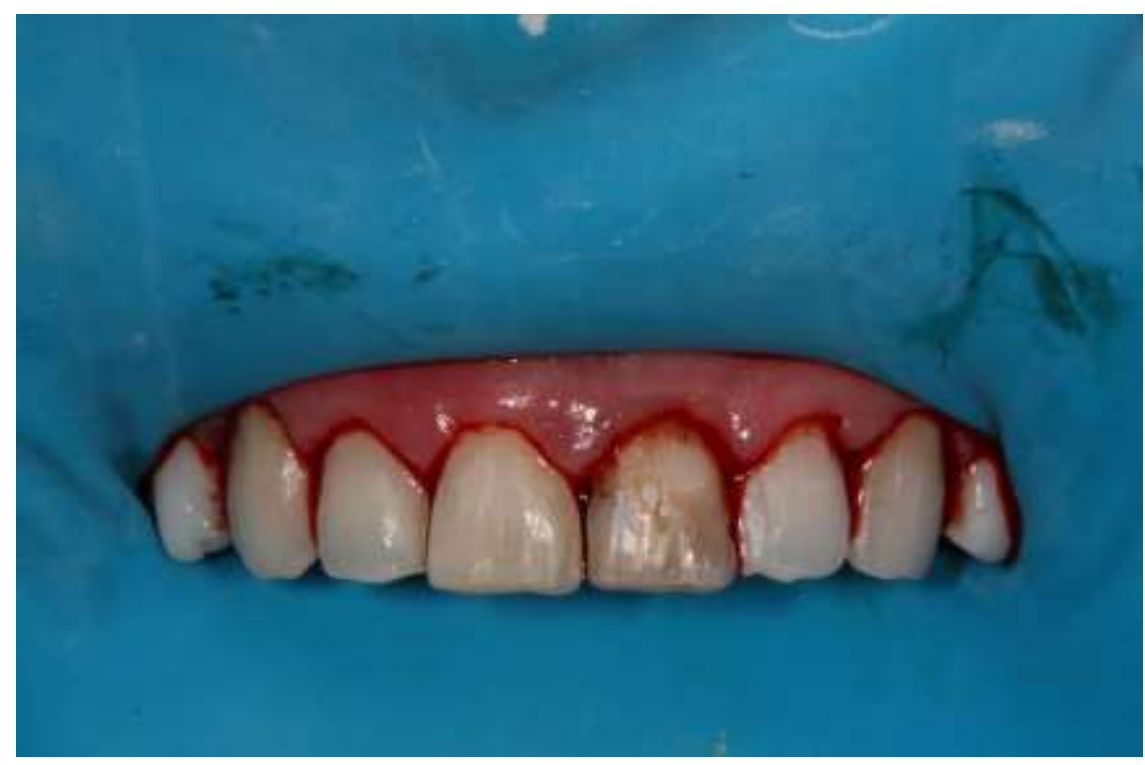

Fonte: Autores.

Posteriormente foi executado um pequeno desgaste com broca 18 lâminas no elemento dentário 21 para melhora da aparência escurecida. A resina escolhida para as novas facetas foi a z350 (3M), na cor wd para dentina e we para esmalte. Após a escolha das cores, foi realizado o posicionamento do fio retrator 000 (Ultradent) (Figura 3).

Figura 3: Preparo do elemento 21 e utilização do fio retrator 000.

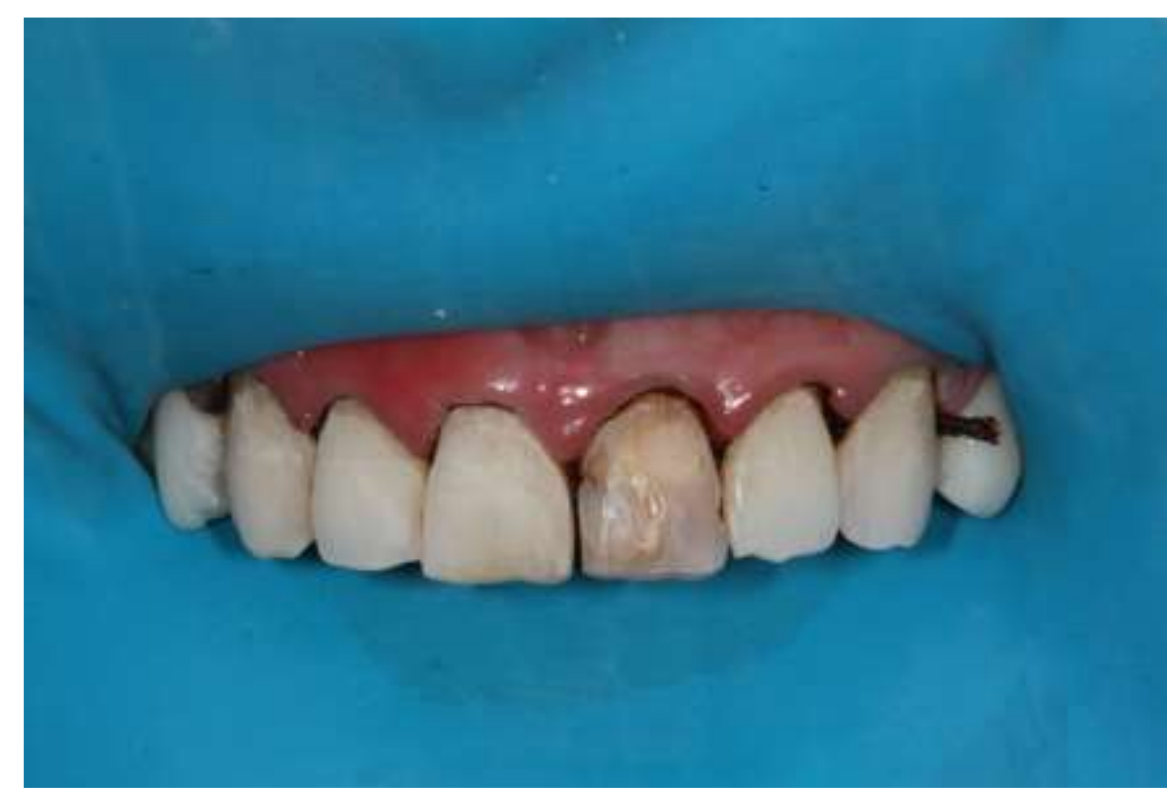

Fonte: Autores.

Em seguida, foi realizado o condicionamento ácido com ácido fosfórico 37\% (ultra-etch) por 30 segundos nos elementos a serem restaurados e em seguida, após lavagem abundante, a aplicação do sistema adesivo (universal 3M) que foi polimerizado por 20 segundos para dar início à incrementação da resina.

Inicialmente foi realizada a criação da muralha palatina com resina ct z350 (3M) e após posicionamento da mesma, fotopolimerização por 20 segundos. Em seguida foi inserida a resina wd z350 (3M) em dentina com auxílio da espátula opra 
esculp e campo roller. Com a própria espátula foi realizada a escultura e estratificação da borda incisal e após fotopolimerização foi inserida a resina we z350 (3M) em toda a face vestibular da unidade dental, acomodação da resina com pincel 00 (Tokuyama) e escultura com a espátula para assim realizar a fotoativação final por 40 segundos.

Logo após a remoção do isolamento absoluto modificado foi realizado ajuste oclusal para distribuição de contatos dentais e acabamento das restaurações com a broca 18 lâminas tronco-cônica, disco de lixa pop on (3M), sequência de borrachas jiffy (Ultradent), disco de feltro (Cosmedent) e pasta para polimento (Enamalize) (Figura 4).

Figura 4: Resultado após a realização das facetas diretas em resina composta.

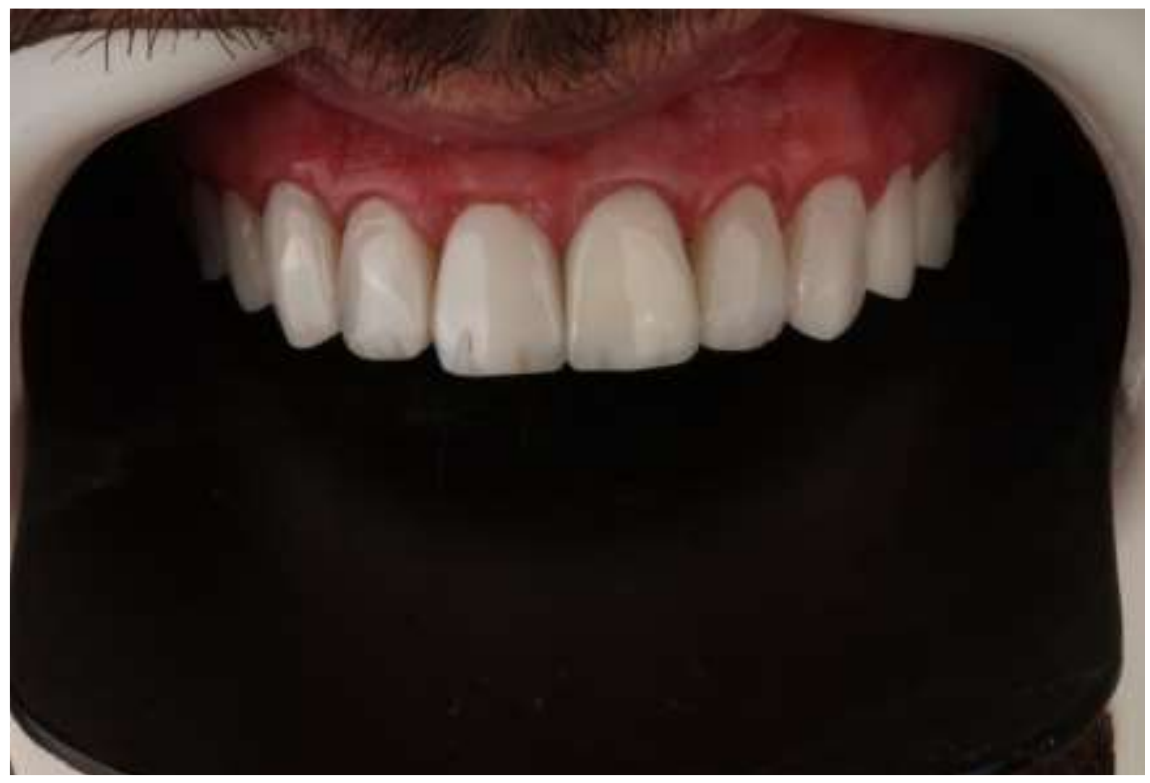

Fonte: Autores.

\section{Discussão}

De acordo com Moura (2017) o Cirurgião-Dentista deve realizar um correto diagnóstico e detalhado plano de tratamento, contemplando seus conhecimentos científicos e a percepção das possibilidades restauradoras, bem como as necessidades funcionais, emocionais, estéticas e as perspectivas financeiras dos pacientes.

Maranho e Oliveira (2019) também defendem que no planejamento a sequência de procedimentos pode ser uma boa alternativa para obter informações essenciais para a elaboração de um tratamento estético individualizado, a começar por um exame clínico detalhado, que deve ser complementado com a requisição de radiografias, fotografias e modelos de estudo, assim como foi feito no caso clínico apresentado. Planejamento que constitui-se por:

1 - Diálogo objetivando a compreensão da queixa do paciente com relação aos seus dentes e o que o motivou a procurar tratamento odontológico.

2 - Exame clínico minucioso, considerando todos os fatores biológicos, funcionais e estéticos.

3 - Protocolo retratado do complexo orofacial: - Sem afastador labial: frontal lábios em repouso, frontal sorriso natural, frontal sorriso máximo (forçado). - Com afastador labial: frontal e laterais (direita e esquerda) em máxima intercuspidação; visão oclusal (superior e inferior).

4 - Exame radiográfico para entendimento da situação endodôntica e periodontal detalhada: tomada panorâmica e/ou periapicais da região a ser restaurada. 
5 - Obtenção de modelos de estudo do arco superior e inferior independente da área envolvida no tratamento, (para reprodução de movimentos oclusais).

Gregorine (2018) ressalta que é essencial que o profissional leve em consideração as indicações e contra indicações, como também as vantagens e desvantagens de cada técnica, proporcionando assim, um procedimento adequado. Desta forma, no caso clínico citado, o mais indicado era a troca de facetas antigas por novas facetas de resina, pois não necessitava de muito preparo, levando em consideração que o paciente já apresentava um quadro de mobilidade proveniente de um acidente e um maior desgaste comprometeria a estrutura dentária.

Já Santos (2016) afirma que o tratamento não deve se limitar exclusivamente à técnica restauradora. Sendo fundamental a manutenção da saúde bucal e da integridade da forma e cor do arco, para que se tenha equilíbrio da sua estrutura, assim também como uma boa estética. Desta forma, no caso clínico foi optado por realizar um clareamento dental na arcada inferior anteriormente a execução das facetas diretas em resina composta para uma melhor harmonia do sorriso após o fim de todo o tratamento.

Menezes e Vilela (2018) afirmam que é possível obter restaurações minimamente invasivas devido a evolução das técnicas e materiais restauradores que possibilitam a preservação de estrutura dentária sadia, proporcionando maior naturalidade ao sorriso, que pode ser facilitado constituído por enceramento diagnóstico e o ensaio restaurador intraoral, também nomeados respectivamente de wax-up e mock-up. Dessa forma, a alternativa de utilização do planejamento reverso motiva o paciente por permitir maior previsibilidade do tratamento reabilitador final, além de proporcionar ao cirurgiãodentista maior segurança para execução das etapas reabilitadoras e auxiliar como facilitador da técnica restauradora direta por meio de guias de silicone.

Ouro (2017) também afirma que em relação às facetas que exigem uma preparação mínima devem ser recomendadas, sempre que as condições clínicas e laboratoriais o permitam. Tal vantagem consiste em poder preservar tecido dentário saudável e, portanto, oferecem uma excelente alternativa às facetas e coroas tradicionais que necessitam de um desgaste bastante maior e menos conservador. Por outro lado, ele diz que as facetas "sem preparo" que são mal elaboradas ou fabricadas, podem influenciar negativamente a forma dos dentes do paciente, ou até levar a problemas periodontais, como foi o caso do paciente citado no caso.

No que diz respeito à realização de facetas em resinas compostas, estas permitem a realização de preparos mais conservadores, com o benefício de uma única sessão e sem etapas laboratoriais, o que reduz o seu custo. Apresentam maior resistência, facilidade de reparação e baixa abrasividade relativamente ao desgaste de dentes antagonistas, o que permite a sua aplicação em pacientes que apresentam hábitos parafuncionais. As desvantagens que associam à sua utilização estão diretamente ligadas com o fato de estas apresentarem menor resistência à mastigação, instabilidade da cor e dificuldade de mascarar substratos escurecidos por translucidez, possui porosidade aliada a uma técnica de polimento exigente e demorado, e maior infiltração marginal quando comparadas com a cerâmica. Por este motivo, foi necessário executar o preparo do elemento 21, que possuía um escurecimento e consequentemente poderia comprometer o resultado final (Ouro, 2017).

Cardoso (2018) diz que a elaboração de facetas diretas em resina composta apresenta vantagens, como o menor custo, a rapidez e facilidade de reparação. Porém concorda que há desvantagens consideráveis quando comparadas às facetas cerâmicas e propícias à descoloração e ao desgaste.

Silva (2020) acrescenta que a resina pode ser falha em sua adesão, formando fendas marginais, consequentemente resultando em microinfiltração, resultantes da contração de fotopolimerização.

De acordo com Borba (2021), para se obter sucesso nos tratamentos restauradores, unindo estética e saúde, é extremamente necessário preservar os princípios periodontais. O posicionamento marginal das restaurações e/ou facetas 
influencia diretamente na saúde do periodonto. Quando colocadas subgengivalmente, muitas vezes acabam causando danos ao periodonto, como foi o caso do paciente citado no caso, onde houve invasão do espaço biológico, causando incômodo e sangramento ao paciente.

Muitos profissionais, ao realizarem procedimentos estéticos, acabam não dando a devida importância a tais princípios essenciais, muitas vezes por falta de conhecimento ou até mesmo por pura negligência. Todo e qualquer procedimento restaurador precisa ser compatível com o periodonto e deve prezar pela integridade biológica, pois os dentes naturais dependem dos tecidos periodontais de sustentação e proteção, fazendo eles também, parte da estética do sorriso. (Borba, 2021). Na primeira imagem do caso clínico, podemos notar o aspecto de "inchaço" das gengivas, causado pela invasão do espaço biológico.

Barboni (2020), também defende a preservação da saúde periodontal e ainda afirma que é necessário ter conhecimento sobre o normal para que se possa diagnosticar e solucionar o anormal. Desta forma, é considerado que um periodonto íntegro é aquele que apresenta ligamento periodontal, cemento radicular, osso alveolar e gengiva saudáveis, dando ênfase a coloração rósea da gengiva, consistência firme, pontilhados em sua superfície e com margens bem arredondadas e definidas.

A inserção supracrestal é uma estrutura de suma importância para manutenção de saúde periodontal, pois os fluidos gengivais presentes em seu interior, geram uma barreira contra patógenos, como por exemplo, entre a crista óssea e a placa bacteriana. Sendo a sua integridade violada, os patógenos poderão ter acesso ao tecido ósseo, resultando em graves danos periodontais. (Marques, 2018).

Desta forma, Borba (2021), aponta em sua pesquisa que quando as margens das facetas são posicionadas subgengivalmente, consequentemente violando o espaço biológico, afetam diretamente o periodonto, apresentando inflamação e sangramento gengival. Portanto, manter as margens supragengivais é a melhor opção para preservar a saúde dos tecidos e estruturas periodontais, como foi feito na segunda etapa do caso clínico.

Partindo para os princípios estéticos, Ribeiro (2020), ressalta que um ponto muito importante que deve ser bem analisado, seria a escolha correta da resina composta. Em dentes anteriores, a escolha do tamanho das partículas de carga da resina composta faz muita diferença. As resinas nanohíbridas ou nanoparticuladas, são consideradas resinas "universais", pois possuem melhores propriedades mecânicas e ópticas. Além disso, possuem maior capacidade de manutenção e uma das maiores variedades de cores.

Santana et al. (2016), também compartilha do pensamento que para obter sucesso na confecção de facetas em resina composta, é necessário além de uma indicação adequada e bom domínio da técnica, que o profissional saiba fazer uma seleção de cor apropriada para o perfil do paciente, conversando com o mesmo e mostrando que nem sempre o que o paciente quer é o que deve ser feito. Muitas vezes a escolha de uma cor muito clara, sem translucidez, traz o aspecto de artificialidade e posteriormente insatisfação do paciente após o trabalho concluído, como foi observado no caso clínico, onde a cor das facetas era muito clara, sem translucidez e completamente diferente da cor dos dentes naturais, trazendo um aspecto muito artificial. Por este motivo deve-se manter a ética e escolher o mais indicado para cada paciente.

Outra etapa que muitas vezes acaba sendo negligenciada é a de acabamento e polimento. Essas são manobras clínicas de grande importância que otimizam a mimetização dos dentes naturais. Além de melhorar a performance clínica das restaurações com o passar dos anos, a obtenção de uma superfície dentária lisa e polida, traz benefícios à saúde periodontal e também à estética (Santin et al., 2019) No caso clínico é possível observar a falha na execução desta etapa nas facetas antigas, que resultou em um aspecto de dentes vestibularizados, artificiais, sem forma e sem brilho.

Reddy et al. (2021) também concorda que a etapa de acabamento e polimento é umas mais importantes nos tratamentos restauradores, pois aumenta a longevidade da restauração e das facetas diretas. As restaurações e facetas de resina 
composta, se acabadas e polidas na sequência adequada, podem durar muito tempo e proporcionar satisfação ao paciente. Cada etapa, desde a redução bruta até o acabamento e polimento finos, devem ser executadas na sequência correta para obter resultados ideais, assim como foi feito na execução das novas facetas do caso clínico descrito.

$\mathrm{O}$ acabamento remove os excessos de resina composta, trazendo definição à anatomia primária dos dentes. Na etapa de texturização, ocorre a representação de características superficiais da estrutura dental. E por último é realizado o polimento, onde há a suavização da rugosidade, trazendo um aspecto liso e reflexivo, semelhante aos dentes naturais.

Todas essas etapas podem ser uma boa alternativa para solucionar casos clínicos estéticos insatisfatórios (Santin et al., 2019).

\section{Conclusão}

As facetas diretas em resina composta são uma ótima opção para solucionar insatisfações estéticas do sorriso, pois possuem preparos mais conservadores, custo acessível, podem ser realizadas em sessão única e oferecem possibilidade de reparo, além de outras vantagens. Porém, para um bom resultado estético e funcional, se faz necessário uma correta indicação, bom planejamento, que o profissional possua domínio da técnica, respeite os tecidos periodontais, possua conhecimento da anatomia dental e sobretudo mantenha a ética. Seguindo tais princípios, é possível alcançar as expectativas do paciente sem que o mesmo se frustre e necessite ir em busca de outro profissional para refazer o trabalho mal executado.

Sugere-se que os Cirurgiões-dentistas estejam sempre em busca do conhecimento, obtendo novas técnicas e novidades constantes em suas especializações, afim do sucesso clinico e estético, oferecendo qualidade para a saúde bucal dos pacientes que procuram melhorar o seu sorriso.

\section{Referência}

Barboni, K. G. (2021). Problemas periodontais ocasionados pelo insucesso das lentes de contato: Relato de caso. http://rdu.unicesumar.edu.br/handle/123456789/7745

Berwanger, C., Rodrigues, R. B., Ev, L. D., Yamith, A., Denadai, G. D. A., Erhardt, M. C. G., \& Coelho-de-Souza, F. H. (2016). Fechamento de diastema com resina composta direta-relato de caso clínico. Revista da Associacao Paulista de Cirurgioes Dentistas, 70(3), $317-322$.

Borba, J. A. D. (2021). Efeitos das facetas no periodonto: uma revisão integrativa. https://repositorio.animaeducacao.com.br/handle/ANIMA/17200

Borges. M. H. S. et al. (2019). Faceta direta em resina composta: Relato de caso clínico.Revista de Iniciação Científica em Odontologia. 17(2): 111-118. https://acervomais.com.br/index.php/saude/article/view/6439/4263

Cardoso, A. M. (2018). Causas de fracasso e opções de reparação de facetas dentárias de elaboração indireta (Doctoral dissertation). https://bdigital.ufp.pt/handle/10284/7441

de Carvalho, C. S. (2021). A importância do acabamento e polimento em restaurações diretas de resina composta: Revisão de literatura. https://repositorio.animaeducacao.com.br/handle/ANIMA/14246

de Oliveira Rocha, A., Lima, T. O., dos Anjos, L. M., de Sá Santos, L. F., dos Anjos Santos, R. D. M., José, W., ... \& Júnior, N. S. M. (2021). Uso de pino de fibra de vidro para reabilitar unidade dental comprometida por extensa lesão cariosa: relato de caso. Revista Eletrônica Acervo Saúde, $13(6)$, e7847-e7847. https://acervomais.com.br/index.php/saude/article/view/7847.

dos Reis, G. R., Oliveira, L. P. M., Vilela, A. L. R., \& de Sousa Menezes, M. (2018). Mock-up: Previsibilidade e facilitador das restaurações estéticas em resina composta. Revista Odontológica do Brasil Central, 27(81). https://doi.org/10.36065/robrac.v27i81.1131

de Sousa Menezes, M., Vilela, A. L. R., Silva, F. P. S. P., Reis, G. R., \& Borges, M. G. (2014). Acabamento e polimento em resina composta: reprodução do natural. Revista Odontológica do Brasil Central, 23(66). https://doi.org/10.36065/robrac.v23i66.882

Eddy. et al. (2021). Acabamento e polimento de compostos - Uma revisão. IP Indian Journal of Conservative and Endodontics. 6(1):7-10. https://www.ijce.in/html-article/13435

Fontenele, M. A. (2019). Causas de insucessos em facetas de porcelana. http://repositorio.saolucas.edu.br:8080/xmlui/bitstream/handle/1 23456789/3438/ Maryn\%C3\%A1 cia\%20Albuquerque\%20Fontenele \%20-\%20Causas\%20de\%20insucessos $\% 20$ em $\% 20$ facetas $\% 20 \mathrm{de} \% 20$ porcelana.pdf?sequence=1 
Research, Society and Development, v. 10, n. 14, e169101421740, 2021

(CC BY 4.0) | ISSN 2525-3409 | DOI: http://dx.doi.org/10.33448/rsd-v10i14.21740

Gregorini, C. M. (2018). Facetas de cerâmica ou resina composta: qual, por que e como indicar? https: //repositorio.ufsc.br/handle/123456789/191213

Marques, R. O. (2018). Espaço biológico: mito ou realidade (Doctoral dissertation). https://bdigital.ufp.pt/handle/10284/7503

Moura A. B. D. (2018). Facetas de resina composta ou cerâmicas: qual utilizar? Repositório Institucional da Universidade Federal de Santa Catarina. https://repositorio.ufsc.br/handle/123456789/181426

Muziol, T. A. (2017). Protocolo de preparos para facetas diretas em resina composta. 2017. 40 fls. Trabalho de Conclusão de Curso (Graduação em Odontologia) -Universidade Estadual de Londrina, Londrina. http://www.uel.br/graduacao/odontologia/portal/pages/arqu ivos/TCC2017/THAYSA\%20APARECIDA\%20MUZIOL.pdf

Ouro, G. D. M. D. (2017). Facetas em resina composta ou cerâmica: desgaste ou não desgaste? http://hdl.handle.net/20.500.11816/2865

Patias, R. (2015). Sobrevivência de restaurações e facetas de resina composta direta e cerâmicas em dentes anteriores: estudo retrospectivo sobre fatores relacionados à substituição e ao reparo (Master's thesis, Universidade Federal de Pelotas). http://guaiaca.ufpel.edu.br/handle/prefix/3556

Pereira, M. R., Baleeiro, L. L., Coelho, U. P., \& Garcia, N. G. (2020). Reabilitação estética com resina composta em paciente jovem: relato de caso clínico. Revista Odontológica do Brasil Central, 29(88). https://doi.org/10.36065/robrac.v29i88.1296

Sant'anna, G. R. D., Silva, I. M., Lima, R. L., Souza-Zaroni, W. C., Leite, M. F., \& Samiei, M. (2016). Infiltrante resinoso vs Microabrasão no manejo de lesões de mancha branca: relato de caso. Revista da associação Paulista de cirurgiões dentistas, 70(2), 187-197.

Santin, D. C., Scotti, C. K., Velo, M. M. D. A. C., da Silva Camim, F., Mondelli, R. F. L., \& Bombonatti, J. F. S. (2019). Protocolo de acabamento, texturização e polimento para restaurações diretas em resina composta. Clinical and Laboratorial Research in Dentistry. https://doi.org/10.11606/issn.23578041.clrd.2019.152964

Santos, J. A. D. (2016). Abordagem na seleção de materiais para facetas diretas de resina composta na resolução estética em dentes anteriores. https://repositorio.unesp.br/handle/11449/155264

Santos, R. R, et al. (2017) Facetas Diretas em Resina Composta. Universidade de Rio Verde, GO. https://www.unirv.edu.br/conteudos/fck files/files/RAIANE\%20RIBEIRO.pdf

Silva, A. G. D. (2020). Facetas dentais direta e indireta longevidade e resistência: revisão de literatura.http://famamportal.com.br:8 082/jspui/handle/123456789/1978 